The failure to improve results from 1957 to 1967 can be ascribed to two major factors: inaccurate localization and misuse of antibiotics. A third factor which has become more noticeable in recent years is failure to tap the abscess daily. The overall mortality of $40 \%$ is disturbingly high, but unless methods of management of the acute case are revised it is unlikely to be lowered. In the light of the observations made in this paper the following scheme of initial management is suggested.

As soon as the diagnosis of supratentorial abscess is suspected no further lumbar puncture is done and the patient is transferred immediately to a neurosurgical unit, where after clinical assessment: (1) all patients unless known to be hypersensitive are started on penicillin 4 mega units six-hourly; (2) plain $x$-ray films of the skull and chest are taken ; (3) E.N.T. territory is examined to determine whether there is overt middle ear or frontal sinus infection; and (4) E.E.G. and ultrasound are done, but should not be allowed to delay unduly the next steps.

After these preliminary steps the management will depend on the level of consciousness.

$A$ patients who are fully alert should continue on highdosage penicillin and have a brain scan within 48 hours. If the scan is negative, the patient should be treated expectantly with high-dosage antibiotics.

$B$ patients who are drowsy should be given mannitol and high-dosage penicillin, and scanned within 24 hours. If this is not possible then those who have an unequivocal focus of E.N.T. sepsis should have the appropriate burrhole made ; in all other cases ventriculography is indicated. Carotid angiography can only be relied on in these cases to exclude a temporal intracerebral abscess.

$C$ patients who are unconscious should be given mannitol at once, the high-dosage penicillin should be continued, and if they have mastoid or frontal infection the appropriate burrhole should be made; in all other cases if indium or technetium is available for scanning and mannitol has lightened the level of consciousness then a delay of up to three hours for scanning is justifiable; otherwise ventriculography is indicated.
The further management will obviously depend on the results of these first steps, which have been suggested in an effort to lower the mortality of intracranial abscess that appears to be so closely related to the initial decisions in management.

I wish to thank the Board of Governors of St. George's Hospital who supported me financially as Research Assistant in the Department of Neurosurgery, while this study was made. The patients were admitted to Atkinson Morley's Hospital, the National Hospital for Nervous Diseases, and the Wessex Neurological Centre, under the care of Mr. Wylie McKissock, Mr. Lawrence Walsh, Mr. Alan Richardson, and Mr. Jason Brice, to all of whom I wish to express my thanks for permission to study these patients and for advice. Dr. Constance Spittle provided frequent advice on bacteriology and antibiotics,

\section{REFERENCES}

Bligh, A. S., and Rack, P. M. H. (1962). Fournal of Neurosurgery, 19, 483.

Burrows, E. H., Kimber, P. M., and Goddard, B. A. (1968). British Medical fournal, 2, 29.

Gregory, D. H., Messner, R., and Zinneman, H. H. (1967). Archives of Internal Medicine, 119, 25.

Jones, N. L., and Fletcher, C. M. (1967). Hospital Medicine, 2, 307. Jooma, O. V., Pennybacker, J. B., and Tutton, G. K. (1951). Fournal of Neurology, Neurosurgery and Psychiatry, 14, 308.

Kerr, F. W. L., King, R. B., and Meagher, J. N. (1958). Fournal of the American Medical Association, 168, 868.

Krayenbühl, H. A. (1967). Clinical Neurosurgery, 14, 25.

Krayenbühl, H. A. (1967). Clinical Neurosurgery, 14,

Macewen, W. (1893). Pyogenic Infective Diseases of the Brain and Spinal Cord. Maclehose, Glasgow.

Overton, M. C., Haynie, T. P., and Snodgrass, S. R. (1965). Fournal of the American Medical Association, 191, 431

Pennybacker, J. (1945). Proceedings of the Royal Society of Medicine, 38,431 .

Pennybacker, J. (1951). In Modern Trends in Neurology, Series I, p. 257, edited by A. Fieling. Butterworth, London.

Pennybacker, J. (1961). Proceedings of the Royal Society of Medicine, 54,309 .

Planiol, T. (1966). Progress in Neurological Surgery, 1, 95.

Schurr, P. H. (1951). British Fournal of Surgery, 39, 156.

Sweet, W. H., Mealey, J., Aronow, S., and Brownell, G. L. (1961). Clinical Neurosurgery, $7,159$.

Van Eck, J. H. M. (1966). Fournal of Neurosurgery and Psychiatry, 29, 145 .

Webster, J. E., and Gurdjian, E. S. (1950). International Abstracts of Surgery, 90, 209.

\title{
Placental Transfusion as an Intrauterine Phenomenon in Deliveries Complicated by Foetal Distress
}

\author{
ALISTAIR G. S. PHILIP,* M.D., M.R.C.P.ED. ; ANN B. YEE,* M.D. ; MOOTHEDAN ROSY,* M.D., M.R.C.P.ED \\ NERGESH SURTI,* M.D.; A. TSAMTSOURIS,* M.D.; DAVID INGALL, $\dagger$ M.D.
}

\footnotetext{
Summary : The details of the deliveries of 10 infants whose cords were clamped before the onset of respiration and within one minute of delivery of the chin but whose residual placental volumes were unexpectedly low are compared with 20 control infants whose cords were clamped under similar conditions but who had the expected residual placental volumes. The only statistically significant difference between these groups was in the high number of patients with foetal distress and low Apgar scores in the former group. It is concluded that placental transfusion occurred before delivery in these patients and that foetal asphyxia facilitated this transfusion, which may be the underlying mechanism of neonatal erythrocythaemia or transient tachypnoea of the newborn.
}

\section{Introduction}

The resurgence of interest in the potential pathological effects of a postnatal placental transfusion has rekindled interest in the physiology of this phenomenon in man. Lind and co-workers (see Moss and Monset-Couchard, 1967) have done much to further our understanding of the physiological consequences of this postnatal transfer, but little progress has been made in delineating those factors which facilitate or prevent its occurrence. Several factors influence the transfer of blood from

* Research Fellow in the Newborn, Department of Paediatrics, Boston City Hospital and Boston University School of Medicine, Boston, Massachusetts.

† Paediatrician-in-Charge, Newborn Nurseries, Boston City Hospital Associate Professor of Paediatrics and Obstetrics and Gynaecology, Boston University School of Medicine, Boston, Massachusetts. 
placenta to baby, and these include the time interval between delivery of the baby and ligation of the cord, gravity (Gunther, 1957), and uterine contractions (Nyberg and Westin, 1958; Yao et al., 1967). More recent studies have suggested that placental transfusion may be better correlated with the onset of postnatal respiration than with the time of clamping of the umbilical cord (Redmond et al., 1965 ; Kjeldsen and Pedersen, 1967).

During the course of our continuing studies on placental transfusions we accumulated data on 200 newborn infants whose cords were ligated within seconds of delivery of the chin and before the onset of respiration (thus qualifying them for anybody's definition of early clamping). Ten of these infants were noted on analysis to have residual placental volumes that were much lower than expected. The purpose of this communication is to report our observations on these infants and to contrast them with infants who were also "early clamped" but whose residual placental volumes fell in the expected range.

\section{Materials and Methods}

The infants forming the basis of this report were delivered at the Boston City Hospital. In all instances the cord was clamped less than 60 seconds after delivery of the chin and more than 10 seconds before the first breath.

One of us was present at these deliveries and recorded the progress of labour and delivery as previously described (Redmond et al., 1965) as well as any complications of delivery. The residual placental volume was measured (Redmond et al., 1965). The subsequent course of the neonate in the nursery was noted.

Thirty infants form the basis of this report. Group 1 was composed of the 10 infants whose residual placental volumes were less than $55 \mathrm{ml}$. Group 2 consisted of 20 concurrent control infants whose deliveries were the last preceding and the first succeeding each of the deliveries of group 1 and whose residual placental volumes exceeded $55 \mathrm{ml}$. These groups were compared in regard to maternal age, parity, race, gestational age, presentation, duration of labour, method of delivery, complications of delivery, time of delivery of the baby, time of clamping, time of first gasp, time of first cry, time of onset of respiration, one-minute Apgar score, birth weight, and time of delivery of the placenta. These factors were then subjected to statistical analyses.

\section{Results}

Some of the data in group 1 and group 2 are given in the Table. In group 16 of the 10 infants had unequivocal evidence of foetal distress (change in heart rate and/or meconium staining), whereas only 2 of the 20 infants in group 2 had such findings. This difference is significant by the $\chi^{2}$ test with the use of a two-by-two contingency table and the Yates correction factor for small numbers at a $P$ value $<0.02$. In addition, the infants in group 1 had lower Apgar scores (mean 4.9) than the infants in group 2 (mean 8.5). This finding is consistent with asphyxia neonatorum. There was no statistically significant difference between both groups in regard to maternal age,

Comparison of Data in Groups 1 and 2

\begin{tabular}{|c|c|c|c|}
\hline & & $\begin{array}{c}\text { Group } 1 \text { (10 Cases) } \\
\text { Mean } \pm \text { S.E.M. }\end{array}$ & $\begin{array}{c}\text { Group } 2 \text { ( } 20 \text { Cases) } \\
\text { Mean } \pm \text { S.E.M. }\end{array}$ \\
\hline 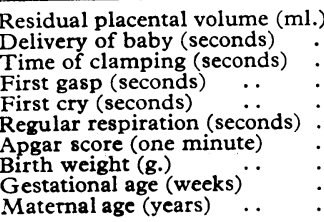 & $\begin{array}{ll}.) & \cdots \\
\because & \cdots \\
\cdots & \cdots \\
\cdots & \cdots \\
\cdots & \cdots \\
\cdots & \cdots \\
\cdots & \cdots\end{array}$ & $\begin{array}{c}44 \pm 4 \cdot 7^{*} \\
46 \pm 8 \\
20 \pm 6 \cdot 6 \\
74 \pm 18 \\
113 \pm 2 \cdot 7 \\
135 \pm 29 \cdot 4 \\
4 \cdot 9 \pm 0 \cdot 46^{*} \\
2,946 \pm 67 \\
39 \cdot 4 \pm 0 \cdot 79 \\
25 \cdot 9 \pm 1 \cdot 97\end{array}$ & $\begin{array}{c}90 \pm 1 \cdot 2 * \\
43 \pm 6 \cdot 2 \\
27 \pm 4 \cdot 3 \\
44 \pm 11 \\
65 \pm 144 \\
97 \pm 14 \cdot 4 \\
8 \cdot 5 \pm 0 \cdot 25^{*} \\
3,098 \pm 128 \\
39 \cdot 5 \pm 0.4 \\
23 \cdot 6 \pm 4 \cdot 936\end{array}$ \\
\hline
\end{tabular}

parity, race, gestational age, presentation of labour, method of delivery, time of first gasp, time of first cry, time of onset of respiration, birth weight, and time of delivery of the placenta.

In the Chart the residual placental volume is plotted against the time of delivery of the chin to clamping of the umbilical cord. The mean residual placental volume in group 2 was $90 \mathrm{ml}$., whereas in group 1 it was $44 \mathrm{ml}$. Although the cords were clamped within 12 seconds of delivery of the chin in half of the babies in group 1, the mean of 20 seconds for the interval between delivery of the chin and clamping was not significantly different from the mean of 27 seconds in the control group.

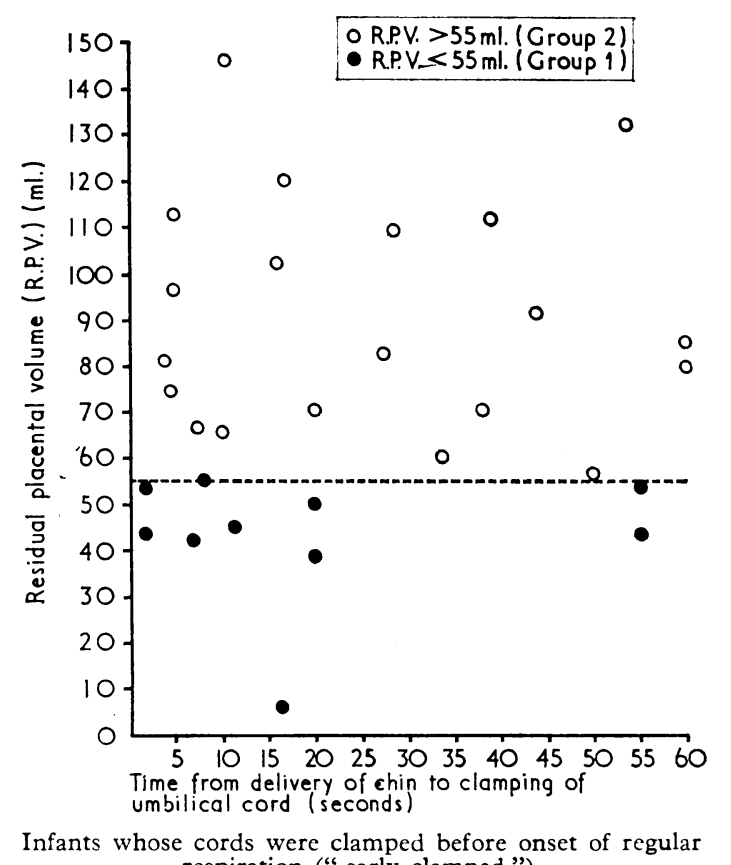
respiration (" early clamped ").

\section{Discussion}

The data contained in the present study are unique. The finding of low residual placental volumes in infants whose cords are clamped within one minute of delivery of the chin and 10 seconds or more before the onset of respiration has been clearly demonstrated. The data become more impressive when considered in the light of our previous investigations (Redmond et al., 1965), since the mean residual placental volume (44 ml.) is remarkably similar to that found in infants who are late clamped. The clinical significance of this observation rests on its occurrence in infants with foetal distress and asphyxia. In addition, the demonstration of small residual placental volumes in asphyxiated babies whose umbilical cords were clamped as early as two seconds after delivery of the chin suggests that the placental transfusion occurred before birth. Since transfer of blood from placenta to baby in normal deliveries uniformly occurs after birth, one might consider the transfer of blood before birth as a pathological event. Our finding of low residual placental volumes in asphyxiated infants supports the work of Yao et al. (1967), who found high blood and red cell volumes in the cord blood of asphyxiated infants delivered by caesarean section.

Previous studies have shown that a placental transfusion is influenced by maternal factors (time of clamping of the umbilical cord, gravity, and uterine contractions). Only recently has the demonstration of the relationship of initial pulmonary aeration to placental transfusion (Redmond et al., 1965) emphasized the contribution of the newborn to this process. The present study provides data that lend further support to the importance of foetal factors in placental transfusion by showing 
that intrauterine placental transfusion may occur in the asphyxiated foetus.

The mechanism(s) of this intrauterine placental transfusion is (are) unclear. Foetal distress and asphyxia were documented clinically in the majority of our infants. In the presence of asphyxia $p \mathrm{H}$ and $\mathrm{PO}_{2}$ fall while $\mathrm{PCO}_{2}$ rises. It is possible that these changes induced respiratory movements in utero (King and Becker, 1964). This intrauterine respiratory activity could then have facilitated the occurrence of placental transfusion on a basis similar to that which occurs with the onset of extrauterine respiration.

In the complex foeto-placental circulation a shift of blood from the placenta to the foetus must involve more flow through the umbilical vein than arteries, otherwise no net transfer of blood could result. In this context the mechanisms underlying our "pathological" placental transfusion may involve factors increasing umbilical venous return or factors decreasing umbilical artery output. The hypoxic induction of uterine contractions could cause placental blood to flow into the foetus. Asphyxia would cause the foetal adrenal glands to secrete earecholamines (Comline and Silver, 1966), which if present in large enough quantities may produce umbilical artery vasoconstriction. The physiological role of thermal factors, mechanical factors, or humoral agents, such as serotonin, bradykinin, and prostaglandins, in umbilical artery constriction after delivery is controversial, hence their function in intrauterine placental transfusion is totally unclear.

The data obtained in the present study raise several questions and reopen several areas of perinatal investigation. Does this pathological prenatal placental transfusion play any significant part in perinatal pathology? Our asphyxiated babies had an uneventful neonatal course. On the other hand, the asphyxiated babies of Burnard and James (1963) had cardiac dilatation and heart failure and may have had a large intrauterine placental transfusion. In addition, neonatal erythrocythaemia (O'Connor et al., 1968) and transient tachypnoea of the newborn (Avery et al., 1966) which has pulmonary radiological features similar to neonatal erythrocythaemia (O'Connor et al., 1968) may be in part produced by the same mechanism.

Other unanswered questions would include: What is the frequency of a prenatal placental transfusion? Does it occur under circumstances other than asphyxia? Does it always occur with asphyxia? Although asphyxia is a frequent antecedent of the respiratory distress syndrome, the haematocrit in this syndrome tends to be in the low normal range, an observation which suggests that an intrauterine placental transfusion did not take place (Inall et al., 1965). Further studies are needed to answer these questions.

This work was aided by a grant from the National Foundation. We would like to thank Dr. David Charles and the Obstetrical Service at the Boston City Hospital for their co-operation in performing this study. We are indebted to Drs. Horace M. Gezon, Robert Klein, Thomas Gardner, and Joseph D. Sherman for their stimulating criticisms in the preparation of this paper.

\section{REFERENCES}

Avery, M. E., Gatewood, O. B., and Brumley, G. (1966). American fournal of Diseases of Children, 111, 380 .

Burnard, E. D., and James, L. S. (1963). Fournal of Pediatrics, 62, 815. Comline, R. S., and Silver, M. (1966). British Medical Bulletin, 22, 16. Gunther, M. (1957). Lancet, 1, 1277.

Inall, J. A., Bluhm, M. M., Kerr, M. M., Douglas, T. A., Hope, C. S. and Hutchison, J. H.' (1965). Archives of Diseases in Childhood, 40, 480 .

King, J. E., and Becker, R. F. (1964). American fournal of Obstetrics and Gynecology, 90, 257.

Kjeldsen, J., and Pedersen, J. (1967). Lancet, 1, 180.

Moss, A. J., and Monset-Couchard, M. (1967). Pediatrics, 40, 109.

Nyberg, R., and Westin, B. (1958). Acta paediatrica, 47, 350 .

O'Connor, J. F., Shapiro, J. H., and Ingall, D. (1968). Radiology, 90, 333.

Redmond, A., Isana, S., and Ingall, D. (1965). Lancet, 1, 283.

Yao, A. C., Wist, A., and Lind, J. (1967). Acta paediatrica, 56, 585.

\title{
Weight-reducing Effect of Diguanides in Obese Non-diabetic Women
}

\author{
J. F. MUNRO,* M.B., M.R.C.P.ED. ; A. C. MACCUISH, $\dagger$ M.B., M.R.C.P.ED. \\ A. MARSHALL, $\ddagger$ M.B., B.SC., M.R.C.P.ED. ; ELIZABETH M. WILSON,§ S.R.D. \\ L. J. P. DUNCAN,\| M.B., B.SC., F.R.C.P.ED.
}

British Medical fournal, 1969, 2, 13-15

\begin{abstract}
Ummary : A double-blind trial was carried out to assess D the weight-reducing effect of the diguanides in $\mathbf{9 0}$ women with refractory obesity and normal oral glucose tolerance. The daily dosage of phenformin and metformin was increased at weekly intervals up to $300 \mathrm{mg}$. and $3 \mathrm{~g}$. respectively, and patients were maintained at this dose or on the maximum they could tolerate without anorexia or other gastrointestinal side-effects. Seventyseven completed the 16-week period of study. There was a statistically significant difference between the mean weight change of the control and the treated groups, but no difference between those treated by phenformin or metformin. The weight-losing influence of the diguanides appeared to be no longer significant after the twelfth week of treatment.
\end{abstract}

\section{Introduction}

Obese insulin-independent diabetics uncontrolled by attempted dieting generally gain weight when treated with a sulphonylurea but lose weight when given a diguanide (Clarke and Duncan, 1968). The present study was undertaken to determine whether or not the diguanides have a weight-reducing influence in obese non-diabetic patients.

\section{Material and Methods}

Ninety-six women aged 21 to 63 years were invited to participate. All had refractory obesity, were clinically obese and overweight by at least $20 \%$ of their ideal, had regularly attended the department for 12 months or more, and had not received an anoretic drug, or appreciably lost weight during the three months preceding the study. None had oedema or was known to have cardiac disease.

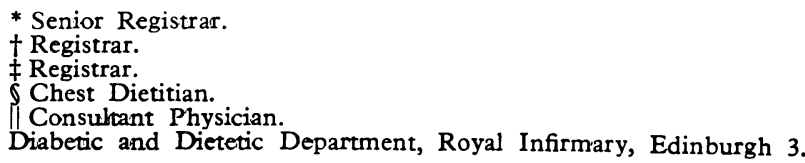

